\title{
Enhancing Usability of Appointment Reminders: Qualitative Interviews of Patients Receiving Care in the Veterans Health Administration
}

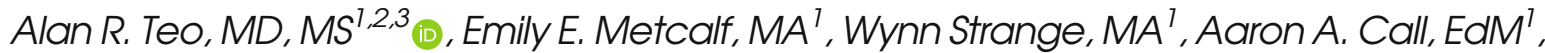 \\ Anaïs Tuepker, $\mathrm{PhD}, \mathrm{MPH} \mathrm{H}^{1,4}$, Steve K. Dobscha, $\mathrm{MD}^{7,2}$, and Peter J. Kaboli, MD, $\mathrm{MS}^{5,6}$
}

\begin{abstract}
'VA Portland Health Care System, HSR\&D Center to Improve Veteran Involvement in Care (CIVIC), Portland, OR, USA; ${ }^{2}$ Department of Psychiatry, Oregon Health \& Science University, Portland, USA; ${ }^{3}$ School of Public Health, Oregon Health \& Science University and Portland State University, Portland, USA; ${ }^{4}$ Division of General Internal Medicine and Geriatrics, Oregon Health \& Science University, Portland, USA; ${ }^{5}$ Comprehensive Access and Delivery Research and Evaluation Center, lowa City Veterans Affairs Healthcare System, lowa City, USA; ${ }^{6}$ Division of General Internal Medicine, Department of Internal Medicine, University of lowa Carver College of Medicine, lowa City, USA.
\end{abstract}

BACKGROUND: No-shows are a persistent and costly problem in all healthcare systems. Because forgetting is a common cause of no-shows, appointment reminders are widely used. However, qualitative research examining appointment reminders and how to improve them is lacking.

OBJECTIVE: To understand how patients experience appointment reminders as part of intervention development for a pragmatic trial of enhanced appointment reminders. DESIGN: Qualitative content analysis

PARTICIPANTS: Twenty-seven patients at a single Department of Veterans Affairs hospital and its satellite clinics

APPROACH: We conducted five waves of interviews using rapid qualitative analysis, in each wave continuing to ask veterans about their experience of reminders. We doublecoded all interviews, used deductive and inductive content analysis to identify themes, and selected quotations that exemplified three themes (limitations, strategies, recommendations).

KEY RESULTS: Interviews showed four limitations on the usability of current appointment reminders which may contribute to no-shows: (1) excessive information within reminders; (2) frustrating telephone systems when calling in response to an appointment reminder; (3) missing or cryptic information about clinic logistics; and (4) reminder fatigue. Patients who were successful at keeping appointments often used specific strategies to optimize the usability of reminders, including (1) using a calendar; (2) heightening visibility; (3) piggybacking; and (4) combining strategies. Our recommendations to enhance reminders are as follows: (1) mix up their content and format; (2) keep them short and simple; (3) add a personal touch; (4) include specifics on clinic location and contact information; (5) time reminders based on the mode of delivery; and (6) hand over control of reminders to patients.

CONCLUSIONS: Appointment reminders are vital to prevent no-shows, but their usability is not optimized for

Electronic supplementary material The online version of this article (https://doi.org/10.1007/s11606-020-06183-5) contains supplementary material, which is available to authorized users.

Received April 10, 2020

Accepted August 24, 2020

Published online September 9, 2020 patients. There is potential for healthcare systems to modify several aspects of the content, timing, and delivery of appointment reminders to be more effective and patientcentered.

KEY WORDS: access to care; no-shows; missed appointments; reminder; military veterans

J Gen Intern Med 36(1):121-8 DOI: $10.1007 / \mathrm{s} 11606-020-06183-5$

(c) Society for General Internal Medicine (This is a U.S. government work and not under copyright protection in the U.S.; foreign copyright protection may apply) 2020

\section{INTRODUCTION}

"No-shows," which are appointments neither attended nor canceled, are a persistent problem in all healthcare systems. They compromise patient access, lengthen wait times, increase health care costs and inefficiencies, and worsen clinical care. ${ }^{1-}$

${ }^{4}$ The Office of Inspector General estimated that in 2008, 5.7 million veterans and their dependents used the Veterans Health Administration and over $12 \%$ of 26.5 million scheduled healthcare appointments were no-shows, which cost the Department of Veterans Affairs (VA) \$564 million that year. 5 , 6 The VA is the largest integrated healthcare system in the USA, with their care population increasing to 6.6 million veterans and their dependents in $2014 .^{6}$ Despite numerous no-show mitigation efforts by VA in the last decade, rates of missed visits have continued to be elevated. From October 1, 2018, to September 30, 2019, the national no-show rate in VA was $12.5 \%$, resulting in a staggering 8.7 million missed outpatient clinic appointments. ${ }^{7}$ In many specialty care clinics, no-show rates are even higher, including mental health, where the no-show rate was $17.7 \%$ that same year.

Attending appointments can be viewed as a health behavior. No-shows have many causes, including factors related to both the patient and to the healthcare system. ${ }^{8}{ }^{9}$ Forgetting is a common reason for missing an appointment, and appointment reminders are a common strategy used to reduce no-shows. VA uses multiple modalities for appointment reminders, 
including letters, postcards, telephone calls, and text messages. A 2015 systematic review concluded that the evidence does not demonstrate that any particular reminder modality is more effective than another. ${ }^{10}$

Due to the size of VA, reminders are used on an extremely large scale. For instance, the Western States Network Consortium Regional Reproduction Center in Sacramento, California prints and mails approximately one million postcard reminders each month (approximately 55,000 per day), and this only covers 36 of 170 VA medical centers and their associated satellite clinics. ${ }^{11}$ In 2018, VA launched automated text message appointment reminders (a program called "VEText" https://www.va.gov/HEALTH/VEText.asp), which in its first year sent over 134 million text message reminders to over 7 million Veterans. ${ }^{12}$ Perhaps most common of all, however, is the traditional printed appointment reminder letter. These reminder letters are printed and mailed (or directly handed if scheduled in-person) at individual VA hospitals and clinics.

While there have been dozens of randomized controlled trials testing the effectiveness of various appointment reminder systems and modes of delivery, there has been exceedingly little qualitative research done on appointment reminders. ${ }^{13}$ Moreover, most research and implementation efforts on noshows have not examined patients' behaviors related to appointment reminders and attendance, instead focusing on their demographic and other characteristics. ${ }^{9}$ Qualitative research is well-suited to understanding patient perspectives, experiences, and behaviors related to appointments. The overarching aim of this manuscript was to gain a patient-informed understanding of veterans' experiences with the usability of appointment reminders within VA.

\section{METHODS}

\section{Recruitment and Participants}

The data in this study were collected as part of an ongoing randomized controlled pragmatic clinical trial ${ }^{14}$ to examine the effectiveness of adding brief motivational messages to appointment reminder letters to act as a nudge ${ }^{15,16}$ to reduce no-shows. As part of the intervention development process for the pragmatic trial, the study team obtained informed consent and conducted interviews with patients from the VA Portland Health Care System, which provided institutional review board approval for the study.

To identify potential interview participants, we used the VA Corporate Data Warehouse (CDW) between December 2018 and February 2019 to identify patients who had at least one upcoming outpatient appointment in either primary care or mental health scheduled in at one of the eight clinic sites within VA Portland Health Care System, which included both large, hospital-based clinics and smaller satellite clinics (called CBOCs). We then used purposive sampling ${ }^{17}$ to recruit participants with diversity across several key characteristics of interest (i.e., gender, military service era, and no-show history). We conducted recruitment in five waves and interviewed a total of 27 patients. Between each wave, we adjusted our sampling to maintain or increase participant diversity and iterated intervention content, which was then presented to participants' in the subsequent wave. The portion of the interview guide exploring how veterans' experience appointment reminders within VA remained the same throughout each wave.

\section{Procedures}

One of the co-authors, an experienced qualitative researcher (AT), conducted all interviews using a semi-structured interview guide that (1) addressed feedback on draft wording for the nudges; (2) reviewed status quo and draft intervention appointment reminder letters; and (3) asked about experiences with attending, missing, and rescheduling appointments.

Interviews were conducted in-person between March and July 2019. All but two interviews were audio recorded and transcribed; due to human error, the original audio recordings were not saved for these interviews. In one case the interviewer produced field notes summarizing the interview content immediately after the interview. In the second case, the mistake was discovered during the interview and the participant summarized their earlier responses, as part of the recorded interview. Interviews ranged from 26 to 70 min (mean of $48 \mathrm{~min}$ ) in length. Participants were compensated \$20.

\section{Data Analysis}

We conducted both deductive and inductive content analysis, ${ }^{18}$ in order to identify unexpected themes as well as themes grounded in a priori categories. First, between each interview wave we conducted rapid qualitative analysis, a team-based iterative data analysis process to review data, make decisions, and collect more data for review to gain an understanding of the participant's perspective. ${ }^{19}$ During our rapid analysis, one co-author (EM) listened to audio recordings of interviews by wave and took notes on the valence and content of reactions to specific nudges and letter design. This information was presented to the research team for analysis between waves of interviews, after which decisions were incorporated into the next wave of interviews for future feedback. This process allowed the research team to make preliminary decisions regarding the design of appointment letter messaging based on participant feedback, followed by testing updated content in future interviews.

Informed by the rapid analysis process, a preliminary codebook was created based on themes identified during that initial review. The full research team collectively reviewed several transcripts and revised the codebook to add additional codes grounded in participants' observations. Codes included semantic and latent interpretations of patients' statements, meaning codes allowed not just for direct statements but interpretation by coders, who reached consensus on such interpretations. A co-author with experience in qualitative data analysis (WS) 
was the primary coder and trained a second coder (KT); coders used Atlas.ti Version 8 for coding and data management. Coders met regularly with the study team to discuss impressions and maintain consistency in coding. At coding completion, the research team examined code reports and developed a three-part analytic framework for the data:

I. Limitations related to usability of current appointment reminders (limitations)

II. Strategies used by patients that maximize usability of appointment reminders (strategies)

III. Recommendations for healthcare systems to enhance appointment reminders (recommendations)

Using this analytic framework, we then examined output from codes to sort data into analytic categories, discussed emergent themes within those categories, and selected quotations that exemplified each theme.

\section{RESULTS}

Summary descriptive characteristics of the 27 participants are provided in Table 1. Ages ranged from 34 to 75 years-old, $67 \%$ were male, $78 \%$ white, and $52 \%$ were Vietnam-era veterans. Patients were recruited evenly from mental health and primary care clinics. Participants had zero to 56 appointments (mean of 14) scheduled in the preceding 2 years. Among patients with prior scheduled appointments, four participants had a low no-show rate $(1-10 \%)$, seven had a

Table 1 Summary Descriptive Characteristics of Participants $(N=$ 27)

\begin{tabular}{|c|c|c|}
\hline & $n$ (range) & \% or mean \\
\hline \multicolumn{3}{|l|}{ Demographics } \\
\hline Age & $(34-75)$ & 60 \\
\hline \multicolumn{3}{|l|}{ Sex } \\
\hline Male & 18 & $66.7 \%$ \\
\hline Female & 9 & $33.3 \%$ \\
\hline \multicolumn{3}{|l|}{ Race/ethnicity } \\
\hline White & 21 & $77.8 \%$ \\
\hline Black or African American & 2 & $7.4 \%$ \\
\hline \multirow{2}{*}{\multicolumn{3}{|c|}{$\begin{array}{l}\text { Nater Hawallan or otner Pacinc } \\
\text { Islander }\end{array}$}} \\
\hline & & \\
\hline Declined to answer & 2 & $7.4 \%$ \\
\hline \multicolumn{3}{|l|}{ Service Era } \\
\hline Iraq & 10 & $33.3 \%$ \\
\hline Vietnam & 13 & $51.9 \%$ \\
\hline Other or Unknown & 4 & $14.8 \%$ \\
\hline \multicolumn{3}{|l|}{ Clinic recruited from } \\
\hline Mental Health & 13 & $48.2 \%$ \\
\hline Primary Care & 14 & $51.9 \%$ \\
\hline \multicolumn{3}{|l|}{ Appointment characteristics } \\
\hline \multicolumn{3}{|l|}{ Appointment history in prior 2 years } \\
\hline Number of appointments scheduled & $(0-56)$ & 14 \\
\hline Number of no-shows & $(0-10)$ & 2 \\
\hline \multicolumn{3}{|l|}{ No-show rate ${ }^{1}$} \\
\hline Patients without no-shows & 5 & $21.7 \%$ \\
\hline Low $(1-10 \%)$ & 4 & $17.4 \%$ \\
\hline Moderate $(11-20 \%)$ & 7 & $30.4 \%$ \\
\hline High $(21+\%)$ & 7 & $30.4 \%$ \\
\hline
\end{tabular}

${ }^{I_{n}=23 \text { for this calculation. Four participants did not have a no-show }}$ rate because they were new patients who, at the time of study enrollment, had an upcoming appointment but had not had any appointments in the prior 2 years moderate no-show rate (11-20\%), and seven had a high noshow rate $(21 \%+)$. We assigned participants pseudonyms in our presentation of results to maintain a sense of their humanity while maintaining privacy. ${ }^{20}$ Table 2 contains a description of each individual participant's characteristics to provide context for their comments below.

We grouped our findings within our analytic framework of (I) limitations, (II) strategies, and (III) recommendations. Four limitations highlighted by patients related to usability of current appointment reminders. Four strategies used by patients who were successful at keeping appointments involved actions when receiving appointment reminders. And six recommendations for healthcare systems to increase the usability of appointment reminders could enhance their content, timing, and mode of delivery. A summary of quotes that support each appointment reminders limitation and recommendation is contained in Table 3.

I. Limitations related to usability of current appointment reminders

Veterans implied, and sometimes directly stated, that repetitive information, frustrating telephone systems, cryptic clinic information, and "reminder fatigue" all contributed to missing appointments.

\section{Excessive information within reminders}

Many patients felt that content contained within appointment reminders was excessive or repetitive. Reminder letters, in particular, tended to be perceived as lengthy or containing "a lot of fine print" (Gloria) for busy patients with limited attention spans. As a result, patients often skimmed - rather than read- reminder letters, with a focus on attending to appointment date, time, and location.

2. Frustrating telephone systems when calling in response to an appointment reminder

When a patient needed to call in response to an appointment reminder - for instance, to reschedule - the experience was highly frustrating to some patients. They strongly preferred having a direct telephone number, or at least an extension, specific to the clinic. Dealing with the telephone tree system to cancel or reschedule was viewed as so time-consuming that, at times, no-showing was preferable.

\section{Missing or cryptic information about clinic logistics}

Patients almost universally complained about the inclusion of indecipherable and impenetrable clinic names in mailed appointment reminders. Appointment reminders included clinic names that appeared as a code, rather than simply stating where and with whom the appointment is. One patient succinctly noted: "I'm not in the military anymore. I don't speak abbreviations" (Veronica). Confusion from this was most apparent for patients with appointments at the larger medical center 
Table 2 Descriptive Characteristics for Individual Participants $(N=27)$

\begin{tabular}{|c|c|c|c|c|c|c|c|c|c|}
\hline Pseudonym & Age & Sex & Race/ethnicity & $\begin{array}{l}\text { Service } \\
\text { era }\end{array}$ & Clinic & $\begin{array}{l}\text { New/ } \\
\text { Est }\end{array}$ & $\begin{array}{l}\text { Number of } \\
\text { appointments in prior } \\
2 \text { years }\end{array}$ & $\begin{array}{l}\text { Number of no- } \\
\text { shows in prior } \\
2 \text { years }\end{array}$ & $\begin{array}{l}\text { No- } \\
\text { show } \\
\text { rate }\end{array}$ \\
\hline Gloria & 36 & $\mathrm{~F}$ & White & Iraq & $\mathrm{MH}$ & New & 0 & 0 & $\mathrm{n} / \mathrm{a}$ \\
\hline Leeann & 39 & $\mathrm{~F}$ & White & Iraq & MH & New & 0 & 0 & $\mathrm{n} / \mathrm{a}$ \\
\hline Martin & 56 & M & $\begin{array}{l}\text { Native Hawaiian or } \\
\text { other Pacific Islander }\end{array}$ & Other & $\mathrm{MH}$ & New & 0 & 0 & $\mathrm{n} / \mathrm{a}$ \\
\hline Natasha & 59 & $\mathrm{~F}$ & White & Unknown & $\mathrm{PC}$ & New & 0 & 0 & $\mathrm{n} / \mathrm{a}$ \\
\hline Connor & 61 & $\mathrm{M}$ & White & Iraq & $\mathrm{PC}$ & Est & 1 & 0 & $0 \%$ \\
\hline Kyle & 65 & M & White & Iraq & MH & Est & 3 & 0 & $0 \%$ \\
\hline Oscar & 73 & M & White & Vietnam & $\mathrm{PC}$ & Est & 4 & 0 & $0 \%$ \\
\hline Steve & 60 & M & White & Iraq & $\mathrm{MH}$ & Est & 10 & 0 & $0 \%$ \\
\hline Zoe & 64 & $\mathrm{~F}$ & $\begin{array}{l}\text { Black or African } \\
\text { American }\end{array}$ & Iraq & $\mathrm{PC}$ & Est & 5 & 0 & $0 \%$ \\
\hline Justin & 65 & M & Declined to answer & Vietnam & $\mathrm{MH}$ & Est & 29 & 1 & $3 \%$ \\
\hline Haley & 65 & $\mathrm{~F}$ & $\begin{array}{l}\text { Native Hawaiian or } \\
\text { other Pacific Islander }\end{array}$ & Vietnam & $\mathrm{PC}$ & Est & 56 & 2 & $4 \%$ \\
\hline Shannon & 70 & $\mathrm{~F}$ & White & Vietnam & $\mathrm{PC}$ & Est & 41 & 2 & $5 \%$ \\
\hline Ashley & 57 & $\mathrm{~F}$ & White & Other & PC & Est & 54 & 4 & $7 \%$ \\
\hline Andrew & 75 & M & White & Vietnam & $\mathrm{PC}$ & Est & 7 & 1 & $14 \%$ \\
\hline Leon & 64 & M & Declined to answer & Vietnam & $\mathrm{MH}$ & Est & 7 & 1 & $14 \%$ \\
\hline Owen & 63 & M & White & Vietnam & MH & Est & 13 & 2 & $15 \%$ \\
\hline Carl & 73 & M & White & Vietnam & MH & Est & 23 & 4 & $17 \%$ \\
\hline Doug & 70 & M & White & Vietnam & $\mathrm{PC}$ & Est & 6 & 1 & $17 \%$ \\
\hline Larry & 71 & M & White & Vietnam & $\mathrm{PC}$ & Est & 11 & 2 & $18 \%$ \\
\hline Patrice & 66 & $\mathrm{~F}$ & $\begin{array}{l}\text { Black or African } \\
\text { American }\end{array}$ & Vietnam & $\mathrm{MH}$ & Est & 15 & 3 & $20 \%$ \\
\hline Veronica & 61 & $\mathrm{~F}$ & White & Unknown & MH & Est & 4 & 1 & $25 \%$ \\
\hline Tony & 38 & $\mathrm{M}$ & White & Iraq & MH & Est & 9 & 3 & $33 \%$ \\
\hline Jordan & 75 & M & White & Vietnam & $\mathrm{PC}$ & Est & 29 & 10 & $34 \%$ \\
\hline Ben & 40 & M & White & Iraq & $\mathrm{MH}$ & Est & 24 & 9 & $38 \%$ \\
\hline Zak & 34 & $\mathrm{M}$ & White & Iraq & $\mathrm{PC}$ & Est & 10 & 4 & $40 \%$ \\
\hline Brandon & 67 & M & White & Vietnam & $\mathrm{PC}$ & Est & 9 & 4 & $44 \%$ \\
\hline Clint & 65 & $\mathrm{M}$ & White & Vietnam & $\mathrm{PC}$ & Est & 2 & 1 & $50 \%$ \\
\hline
\end{tabular}

F, female; $M$, male; $M H$, mental health; $P C$, primary care; New, new patient; Est, established patient

sites where there were multiple departments and buildings.

\section{Reminder fatigue}

Patients described receiving multiple appointment reminders from up to five different sources or modalities (i.e., letter, postcard, telephone call, text message, email/secure message). Patients who are regular users of the VA receive a monthly barrage of information which can lead them to discard mailed appointment reminders. Patients who received reminders as text messages commented on the additional redundancy of multiple texts for the same appointment. Making matters even worse, reminders did not take in account whether a patient has already received or responded to a reminder. Taken together, these circumstances led to patients feeling that repeated appointment reminders were excessive and superfluous.

II. Strategies used by patients that maximize usability of appointment reminders

Veterans who were successful at keeping appointments often reported using specific strategies, techniques, and tools when receiving appointment reminders. We identified four strategies: (1) using a calendar; (2) heightening visibility; (3) piggybacking; and (4) combining strategies.

1. Using a calendar
The most common strategy, by far, was transferring information from the appointment reminder to an electronic or paper calendar. One patient commented, "I read them usually as soon as I get it. Then I put it on my calendar... I have a calendar on the wall" (Carl).

\section{Heightening visibility}

Another common strategy was to heighten the visibility of an appointment reminder. Patients frequently highlighted information on appointment reminder letters or put appointment reminder information in a predictable location encountered on a daily basis. Examples of locations included a white board (Kyle), the refrigerator (Patrice), a doorway (Zoe), and the front seat of the car (Shannon).

\section{Piggybacking}

A smaller number of patients used "piggybacking," a strategy in which a person links or associates a new behavior with another established behavior (i.e., habit). ${ }^{21}$ Shannon, for instance, described putting appointment reminders by the coffee pot since she uses it every morning.

\section{Combining strategies}

The final technique we identified was combining strategies. Doug explained, "I write all my appointments down. Then after... I put that in my file basket... And if it's important... after I write it in, I'll highlight it. So it just kind of sticks out. 
Table 3 Summary of Limitations of Appointment Reminders and Related Recommendations with Examples of Supporting Quotes

$\overline{\text { Finding }}$ Example

I) Limitations related to usability of current appointment reminders

1) Excessive information within reminders

2) Frustrating telephone systems when calling in response to an appointment reminder

already pretty much know what it is. (Justin)

But the average person, they are going to glance. They're going to glance at probably the first five or six lines and they are done... That's just the average person. (Veronica) When I have to call, good God. It's like seriously pulling teeth. I do not want to call. It's easier just to miss the appointment because you call the VA - 'if it's an emergency...' you have to listen to that big old spiel at the beginning. (Tony)

Sometimes I have an aversion to calling them because they do not always work... Or the wait time is redundant, I do not want to spend 30 minutes waiting on somebody to answer. (Steve)

3) Missing or cryptic information about clinic logistics Yeah, this one says fourth floor, the main hospital, POPS unit [Short Stay Care Unit/POPS]. And this one does not say anything. It just says EKG OUT PT 4A103. (Kyle)

Even the phone calls you get. This is the VA calling you about an appointment with the VA. Where? You have a thousand departments. (Veronica)

4) Reminder fatigue

Too many [texts come]. I've already said yes, I'm going to attend the appointment. Why do you keep sending me the same appointment information every three days? (Steve)

I get texts. And I get calls. And if you answer one, it does not matter. You still get the other one and it seems redundant... It is repetitive. You get a text and you get a card, or you get a text and you get a letter, or you get some combination of the two. At the end of the day it costs the VA money to do redundancy. (Clint)

III) Recommendations for healthcare systems to enhance appointment reminders

1. Mix up their content and format

I feel like if I see these a couple of times in a row, and then if I see this one, I'm going to be like - oh, what are they doing? I would notice because I've got another inch and a half.

That's a lot of space. Your eyes should catch that difference. I feel like the difference will make people read more.... It would make me read it again. (Zak)

When I see something different, I usually at least read it once. But then if it's the same hat every time, then I do not. (Leon)

They send me a letter in the mail. Sometimes they call, depending. And it's all very bland. With [attention deficit disorder], I need something to stick out in my mind. I need a little bit of flair - something to catch my eye.... Even just changing the color of the paper slightly so it sticks out ... a slightly yellow piece of paper or a slightly off-color piece of paper. My eye is going to catch it, and I'm going to be more likely to look at it. (Ben)

2. Keep them short and simple

3. Add a personal touch

The shorter it is, to me, the better. (Oscar)

Trim unnecessary formalities such as "the 'Dear' because it's not really a letter, it's an appointment reminder (Gloria)

Yeah, [when the VA uses 'you'], that's accountability. And I think a lot of veterans are really big on accountability, because that was something that was-it's always just engrained in us. You are responsible. It is you. (Gloria)

That's telling me what to do. This [with "please"] is asking me what to do. I got told what to do every day for every minute I was in the military. I do not need to hear that crap anymore. Throw it in the trash can. But if you ask me, I'll answer you. (Steve)

I'm looking at the date, clinic, location. I'm just seeing if this thing has directions. This appointment is located on P2 level of building 104, across from the main hospital at the address below. Now this would be a good example. Which one is building 104? This would be easy, if on the back side, you have a map of the facility here. (Connor)

I always get confused on this part of the clinic, because the abbreviations and numbers, I do not really understand. I'm always like, oh yeah, MH I think is mental health, but I do not really know. I think if it spelled it out ... in full instead of just the code for it. (Gloria) Yeah, [the letter's] good because it's not so early you put it someplace you forget where it is, but it's within time so you can make arrangements for transportation and stuff. (Patrice) I do not ever remember the letter. The text message is what always gets me. I would like it the day before... Because, like everybody else, we are running around like crazy doing whatever we are doing, and we'll forget we have an appointment the next day. I do it all the time. I've missed a lot of appointments because I've completely forgotten and gone and done something else. (Zak)

[I get a reminder text in advance by] at least two days. Which I like. It's not too far out where I'm going to forget. Two days is usually a good reminder. Yep, my appointment is still on this day at this time. (Leann)

I wish I could opt out of the letter. Because I think it's a waste of paper, personally, for me.

6. Hand over control of reminders to patients Paper, postage, for the government to spend.... (Leann)

Because I'm color blind, too.” Larry added, “...Y You've got to have a book like mine, and I've still got a calendar and then I get letters, and between the three, I'm fine."

III. Recommendations for healthcare systems to enhance appointment reminders
Six recommendations based on patients' experiences with current appointment reminders were developed, of which four relate to content, one timing, and one mode of delivery (see Fig. 1). The following quotations contextualize each recommendation.

1. Mix up their content and format 


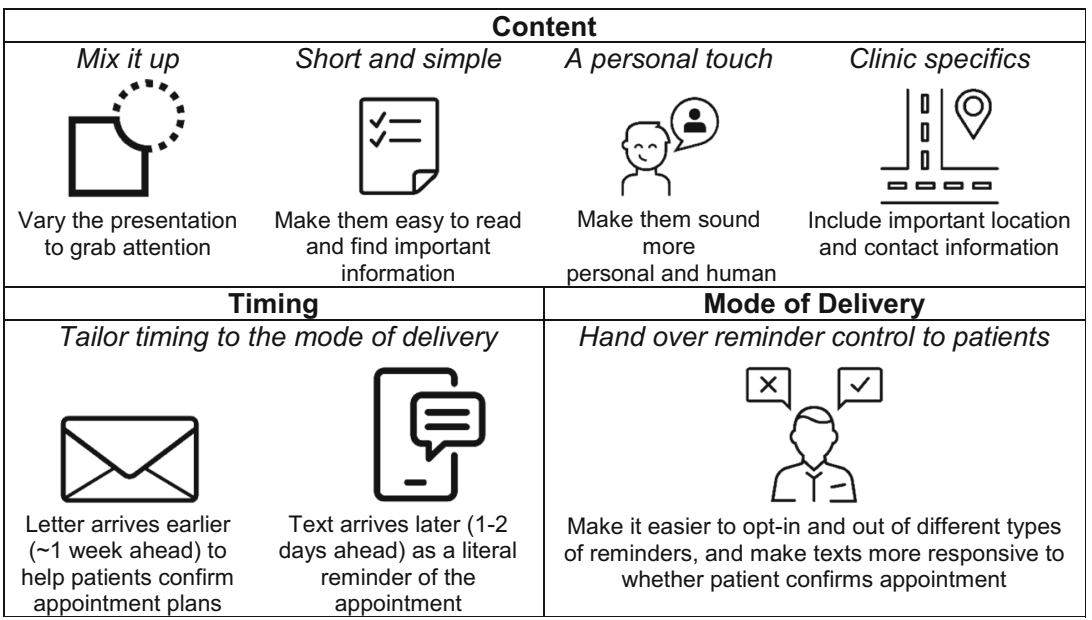

Figure 1 Summary of patient-centered recommendations for enhancing appointment reminders.

Veterans noted that they are likely to tune out, or even ignore, appointment reminders that appear the same, and that varying appointment reminders might prompt them to examine the content more closely. This effect might be achieved by adding new content on a rotating basis, altering the length, or otherwise changing the appearance or format of reminders.

\section{Keep them short and simple}

Rather than having to read through a lengthy letter and hunt for appointment information, some patients often advocated for simplicity. In terms of key content, Tony suggested focusing on important information such as appointment location, time, date, and how to cancel. However, not everyone agreed with this approach: "If it was longer, I would read it more in depth, because I would be like - that doesn't look normal.... I would be like-whoa this looks different than the last one." (Leann).

\section{Add a personal touch}

While patients were familiar with receiving very direct communication from the military, most preferred appointment reminders that were more personable and "human" (Patrice). They generally liked reminders that struck the tone of a request rather than a demand. Selectively (not excessively) using words such as "please" and "you" would accomplish this without sounding like "begging" (Carl).

4. Include specifics on clinic location and contact information

Including detail about the location and contact information for a clinic was viewed as vital. Some appointment reminders (particularly for new patient appointments) could be improved by including information such as a map, the precise location of a clinic within a hospital, and a specific phone extension for a clinic.

5. Time reminders based on the mode of delivery
Patients often described a preference for appointment reminder letters and postcards to be delivered further in advance of an appointment - typically about 1 week-than other types of reminders. This was because these reminders were often most useful to help confirm details of an appointment and trigger any advance planning necessary for the appointment. In contrast, text messages - typically received 1 or 2 days before the appointment - often served more literally as a reminder for an appointment.

\section{Hand over control of reminders to patients}

Patients want a say in the types of reminders they receive. They described different functions that reminders serve depending on how they are reminded, and they valued receiving more than one type of appointment reminder (e.g., text message and mailed letter). Multiple reminder modalities may be especially beneficial in subgroups of patients at higher risk of no-showing.

However, patients also emphasized the danger of reminder fatigue. Having a clear opt-out or opt-in system would allow patients to decide what types of reminders work well for them. Leann noted, "I wish I could opt out of the letter. Because I think it's a waste of paper, personally, for me. Paper, postage, for the government to spend...." A related preference was for improved responsiveness to patient feedback, especially with respect to text message reminders that employed two-way communication. Connor suggested not sending additional reminders once a patient has confirmed an appointment: "Or you might even have the ability - another option is, no further texts. I'm coming, no further texts...." Conversely, an additional reminder could be provided when a patient has not confirmed an appointment.

\section{DISCUSSION}

Our findings revealed that current appointment reminders are limited in terms of their usability for patients. Perhaps as a consequence of this, patients have devised strategies to make 
the best of these reminders. There are certain patient behaviors that can overcome some of these limitations, and we have described several of these patient behaviors in our results related to strategies to optimize the usability of reminders. In addition to patient behaviors, there are also actions healthcare systems can take to enhance the usability of reminders. Informed by patients' experiences, we identified six recommendations that build off the existing framework for appointment reminders while further optimizing their effectiveness. These recommendations include four suggestions related to reminder content, one related to timing, and one related to delivery mode (Fig. 1).

When considering the complexity of large integrated healthcare systems, compared with interventions that require developing new systems and processes, many of our recommendations are relatively amenable to implementation, such as changing the content contained in existing reminders. In addition, our findings suggest other opportunities to enhance reminder systems worth exploring include simplifying telephone systems to make it easier to reach scheduling staff and offering skill trainings for patients with a history of repeated no-shows to more effectively manage their appointments.

Several of our findings are strengthened by their alignment with existing behavior change theory and practice. For instance, the strategy of heightening the visibility of an appointment reminder is similar to the concept of salience, the degree to which something garners a person's attention. ${ }^{22}$ Also, patients who put their appointment reminders in a place they encounter every day are tapping into the behavior change strategy known as piggybacking. ${ }^{21}$ Some of the recommendations, such as "keep it simple" and "mix it up," parallel suggestions in the realm of "sticky" ideas and learning. ${ }^{23}$

Our study has several limitations. First, we only interviewed 27 veterans in the VA's integrated healthcare system in one region of the USA, and thus our findings may not be generalizable to a more general population. Second, our results focused on patients' experiences with outpatient clinic appointments for which they receive printed appointment reminder letters. Reminders designed for other types of healthcare services - particularly distinctive, "one-time" services such as a surgery or diagnostic procedure - may require separate consideration. Additionally, implementation of our recommendations requires developing a nuanced understanding of the barriers and facilitators to changing appointment reminders, particularly when considering the complexity of large integrated healthcare systems. Finally, randomized controlled trials (RCTs) are needed to definitively determine whether these recommendations translate into reduced improved outcomes such as fewer no-shows. Some of our recommendations (e.g., timing of reminder phone calls) have been examined in RCTs. ${ }^{24}$

Notwithstanding these limitations, it is clear that a tremendous amount of effort goes into distributing appointment reminders, and our results suggest that poorly received reminders may actually be counterproductive. Applying user feedback into reminder design seems a promising, low-cost start towards increasing patient satisfaction. Implementation studies of enhanced appointment reminders would seem an important next step in research, particularly considering how commonly employed appointment reminders are in healthcare systems. ${ }^{25}$ The value of improving patient satisfaction is worth underscoring in an environment where patients - in VA as well as other healthcare systems - have choices for where they get their care.

In conclusion, this study builds upon the existing literature by describing four limitations of current appointment reminders and providing six patient-informed recommendations for improving appointment reminders. As healthcare systems struggle to optimize clinic access and minimize no-shows, these insights can help design improved systems of care that are more efficient and meet the needs that patients themselves identify.

Corresponding Author: Alan R. Teo, MD, MS; School of Public Health, Oregon Health \& Science University and Portland State University, Portland, USA (e-mail: teoa@ohsu.edu).

Funding This study was supported by a grant (IIR 17-134) from the Department of Veterans Affairs, Veterans Health Administration, Office of Research and Development, Health Services Research and Development (HSR\&D). This manuscript is not under review elsewhere and there is no prior publication of manuscript contents. The views expressed in this article are those of the authors and do not necessarily represent the views of the Department of Veterans Affairs or the United States Government.

\section{Compliance with Ethical Standards:}

Conflict of Interest: The authors declare that they do not have a conflict of interest.

\section{REFERENCES}

1. Davies ML, Goffman RM, May JH, et al. Large-scale no-show patterns and distributions for clinic operational research. Healthcare (Basel). 2016;4(1): 15. https://doi.org/10.3390/healthcare4010015.

2. Hwang AS, Atlas SJ, Cronin P, et al. Appointment "no-shows" are an independent predictor of subsequent quality of care and resource utilization outcomes. J Gen Intern Med. 2015;30(10):1426-1433. https://doi.org/10.1007/s11606-015-3252-3.

3. Nelson EA, Maruish ME, Axler JL. Effects of discharge planning and compliance with outpatient appointments on readmission rates. Psychiatr Serv 2000;51(7):885-889. https://doi.org/10.1176/appi.ps.51.7.885.

4. Sparr LF, Moffitt MC, Ward MF. Missed psychiatric appointments: who returns and who stays away. Am J Psychiatry. 1993;150(5):801-805. https://doi.org/10.1176/ajp.150.5.801.

5. Audit of Veterans Health Administration's Efforts to Reduce Unused Outpatient Appointments. VA Office of Inspector General; 2008.

6. Bagalman E. The Number of Veterans That Use VA Health Care Services: A Fact Sheet. U.S. Congressional Research Service. 2014. Accessed May 28, 2020. https://fas.org/sgp/crs/misc/R43579.pdf.

7. VA Informatics and Computing Infrastructure (VINCI). No Show and Cancellation Summary Report. Internal U.S. Department of Veterans Affairs Report: Unpublished; Accessed March 6, 2020.

8. Lacy NL, Paulman A, Reuter MD, Lovejoy B. Why we don't come: patient perceptions on no-shows. Ann Fam Med. 2004;2(6):541-545. https://doi.org/10.1370/afm. 123.

9. Dantas LF, Fleck JL, Cyrino Oliveira FL, Hamacher S. No-shows in appointment scheduling - a systematic literature review. Health Policy. 
2018;122(4):412-421. https://doi.org/10.1016/j.healthpol.2018.02. 002.

10. Peterson K, McCleery E, Anderson J, Waldrip K, Helfand M. Evidence brief: comparative effectiveness of appointment recall reminder procedures for follow-up appointments. Evidence-based Synthesis Program (ESP) Coordinating Center. 2015.

11. Clay Donya. Support Service Specialist. Email communication re: mailed appointment reminders. Published online March 10, 2020.

12. VA employee technical innovation reduces nationwide appointment no-shows. Digital VA. Published January 7, 2020. https://www.oit. va.gov/news/article/index.cfm?read=va-employee-technical-innovation-reduces-nationwide-appointment-no-shows. Accessed 28 May 2020 .

13. McLean SM, Booth A, Gee M, et al. Appointment reminder systems are effective but not optimal: results of a systematic review and evidence synthesis employing realist principles. Patient Prefer Adherence. 2016; 10:479-499. https://doi.org/10.2147/PPA.S93046

14. Ford I, Norrie J. Pragmatic trials. Drazen JM, Harrington DP, McMurray JJV, Ware JH, Woodcock J, eds. N Engl J Med. 2016;375(5):454-463. https://doi.org/10.1056/NEJMra1510059

15. Hausman DM, Welch B. Debate: to nudge or not to nudge*. J Polit Philos. 2010;18(1):123-136. https://doi.org/10.1111/j.1467-9760. 2009.00351.x

16. Thaler RH, Sunstein CR. Nudge: improving decisions about health, wealth, and happiness. Yale University Press. 2008.

17. Palinkas LA, Horwitz SM, Green CA, Wisdom JP, Duan N, Hoagwood K. Purposeful sampling for qualitative data collection and analysis in mixed method implementation research. Admin Pol Ment Health 2015;42(5):533-544. https://doi.org/10.1007/s10488-013-0528-y.

18. Vaismoradi $\mathbf{M}$, Turunen $\mathbf{H}$, Bondas $\mathbf{T}$. Content analysis and thematic analysis: Implications for conducting a qualitative descriptive study: Qualitative descriptive study. Nurs Health Sci 2013;15(3):398-405. https://doi.org/10.1111/nhs. 12048.

19. Beebe $\mathbf{J}$ Rapid Assessment Process: An Introduction. AltaMira Press; 2001.

20. Saunders B, Kitzinger J, Kitzinger C. Anonymising interview data: challenges and compromise in practice. Qual Res 2015;15(5):616-632. https://doi.org/10.1177/1468794114550439.

21. Wood W, Neal D. Healthy through habit: interventions for initiating \& maintaining health behavior change. Behav Sci Policy 2016;2(1):71-83. https://doi.org/10.1353/bsp.2016.0008.

22. Castelo N, Hardy E, House J, Mazar N, Tsai C, Zhao M. Moving citizens online: using salience \& message framing to motivate behavior change. Behav Sci Policy. 2015; 1(2):57-68. https://doi.org/10.1353/bsp.2015.0018

23. Heath C, Heath D. Made to Stick: Why Some Ideas Survive and Others Die. Random House. 2007.

24. Shah SJ, Cronin $\mathbf{P}$, Hong CS, et al. Targeted reminder phone calls to patients at high risk of no-show for primary care appointment: a randomized trial. J Gen Intern Med. Published online August 8, 2016. https://doi.org/10.1007/s11606-016-3813-0

25. Fischer HH, Moore SL, Johnson TL, Everhart RM, Batal H, Davidsoni AJ. Appointment reminders by text message in a safety net health care system: a pragmatic investigation. EGEMS. 2017;5(1).

Publisher's Note Springer Nature remains neutral with regard to jurisdictional claims in published maps and institutional affiliations. 